\title{
Begrenset malignitetsutredning ved idiopatisk venøs trombose
}

\begin{abstract}
BAKGRUNN Sammenhengen mellom venøs trombose og kreft er kjent, men det er ikke enighet om hvor omfattende det skal søkes etter okkult kreft ved venøs trombose uten åpenbar utløsende årsak (idiopatisk venøs trombose). Hensikten med denne studien var å undersøke i hvilken grad begrenset malignitetsutredning hos pasienter med idiopatisk venøs trombose avdekker okkult kreftsykdom.
\end{abstract}

MATERIALE OG METODE Forekomst av kreftsykdom første år etter trombosen ble undersøkt retrospektivt for alle pasienter med idiopatisk venøs trombose ved Bærum sykehus i perioden 1.1. 2003-31.12. 2008. I denne perioden var det rutine å gjøre begrenset malignitetsutredning ved idiopatisk venøs trombose, og vi undersøkte i hvilken grad den begrensede utredning hadde indikert at det kunne foreligge kreftsykdom.

RESULTATER Av 974 pasienter med venøs trombose var det 499 som hadde idiopatisk venøs trombose. 47 av disse $(9,4 \%$; $95 \%$ KI 7,1-12,3) fikk påvist kreftsykdom i løpet av det første året etter trombosen. Begrenset malignitetsutredning avdekket 44 av disse 47 tilfellene $(94 \%)$ og hadde en negativ prediktiv verdi på $99 \%$. Avvik ved begrenset utredning ble funnet hos 98 pasienter (20\%) som ikke fikk påvist kreftsykdom.

FORTOLKNING Nær $10 \%$ av pasientene med idiopatisk venøs trombose fikk påvist kreftsykdom i løpet av det første året. Begrenset utredning med tanke på okkult kreftsykdom avdekket de aller fleste tilfellene.

Trousseaus syndrom, som beskriver overhyppighet av venøs trombose hos kreftpasienter, har vært kjent siden midten av 1800 -tallet (2-4). Noen ganger kan venøs trombose være første tegn på at det foreligger malign sykdom. I $26-47 \%$ av tilfellene er tilstanden uten sikker utløsende årsak og kalles da ofte idiopatisk venøs trombose (5).

Studier viser at det er okkult kreft hos $4-13 \%$ av pasientene med idiopatisk venøs trombose $(3,6-14)$. I tillegg til håndteringen av kreftsykdommen har påvisning av kreft betydning for hvordan trombosen bør behandles (15). Internasjonale retningslinjer anbefaler at pasienter med idiopatisk venøs trombose gjennomgår en begrenset utredning med tanke på underliggende malign sykdom og en mer omfattende utredning der det er unormale funn i den begrensede (16-18).

Det er imidlertid ikke full enighet om hva «begrenset utredning» skal innebære eller hvilke pasienter som bør tilbys mer omfattende utredning. I den eneste randomiserte studien der man har sammenliknet omfattende utredning med ingen utredning med tanke på okkult kreftsykdom, ble det antydet at man kunne oppdage okkult kreftsykdom på et tidligere tidspunkt, men det ble ikke gitt noe klart svar på om det hadde betydning for prognosen (19). Selv om enkelte studier har vist at en del pasienter ved påvisning av okkult kreftsykdom fortsatt har kreft i tidlig stadium (7), er det uklart om tidlig påvisning som følge av omfattende utredning betyr noe for prognose og livskvalitet (6).
Samhandlingsreformen og bruk av de nye perorale antikoagulasjonsmidler som alternativ til lavmolekylært heparin og warfarin gjør at oppfølgingen av pasienter med venøs trombose vil bli overført til primærhelsetjenesten på et tidligere tidspunkt enn før. Det er behov for klare retningslinjer for hva som skal gjøres av utredning og hvem som skal gjøre hva (9).

Ved Tromboseklinikken ved Bærum sykehus har vi siden 2003 fulgt en systematisk, begrenset strategi når det gjelder slik utredning.

Hovedhensikten med denne studien var å undersøke i hvilken grad begrenset malignitetsutredning ved idiopatisk venøs trombose, slik den utøves ved Bærum sykehus, avdekker okkult kreftsykdom. Vi ønsket samtidig å undersøke hvor stor andel av pasientene med idiopatisk venøs trombose som fikk påvist kreft i løpet av det første året etter trombosediagnosen, og om disse skilte seg fra dem som ikke fikk påvist kreft når det gjelder alder, kjønn og trombosens lokalisering.

\section{Materiale og metode}

Journalene til alle pasienter registrert med ICD-10-diagnosekoder for dyp venetrombose og/eller lungeembolisme (alle I80- og I26-koder) ved Bærum sykehus i perioden 1.1. 2003-31.12. 2008 ble gjennomgått for å kontrollere at diagnosekoden var riktig. Hvis det forelå sikker eller overveiende sannsynlig radiologisk diagnose, ble diagnosen ansett som bekreftet. Hvis den radiologiske diagnose var usikker, ble det gjort en
Vigdis Bache Semb

vigdis.semb@vestreviken.no Arnljot Tveit

Avdeling for medisinsk forskning

Bærum sykehus

Engelsk oversettelse på www.tidsskriftet.no

> Se lederartikkel side 378

Denne artikkelen bygger på en masteroppgave ved Institutt for helse og samfunn, Det medisinske fakultet, Universitetet i Oslo (1)

\section{HOVEDBUDSKAP}

Hos pasienter med idiopatisk venøs trombose ble det påvist okkult kreftsykdom hos omkring $10 \%$

En begrenset malignitetsutredning avslørte de aller fleste tilfeller av okkult kreftsykdom

Pasientene med okkult kreftsykdom skilte seg ikke fra de andre pasientene med tanke på alder, kjønn og trombosens lokalisering 


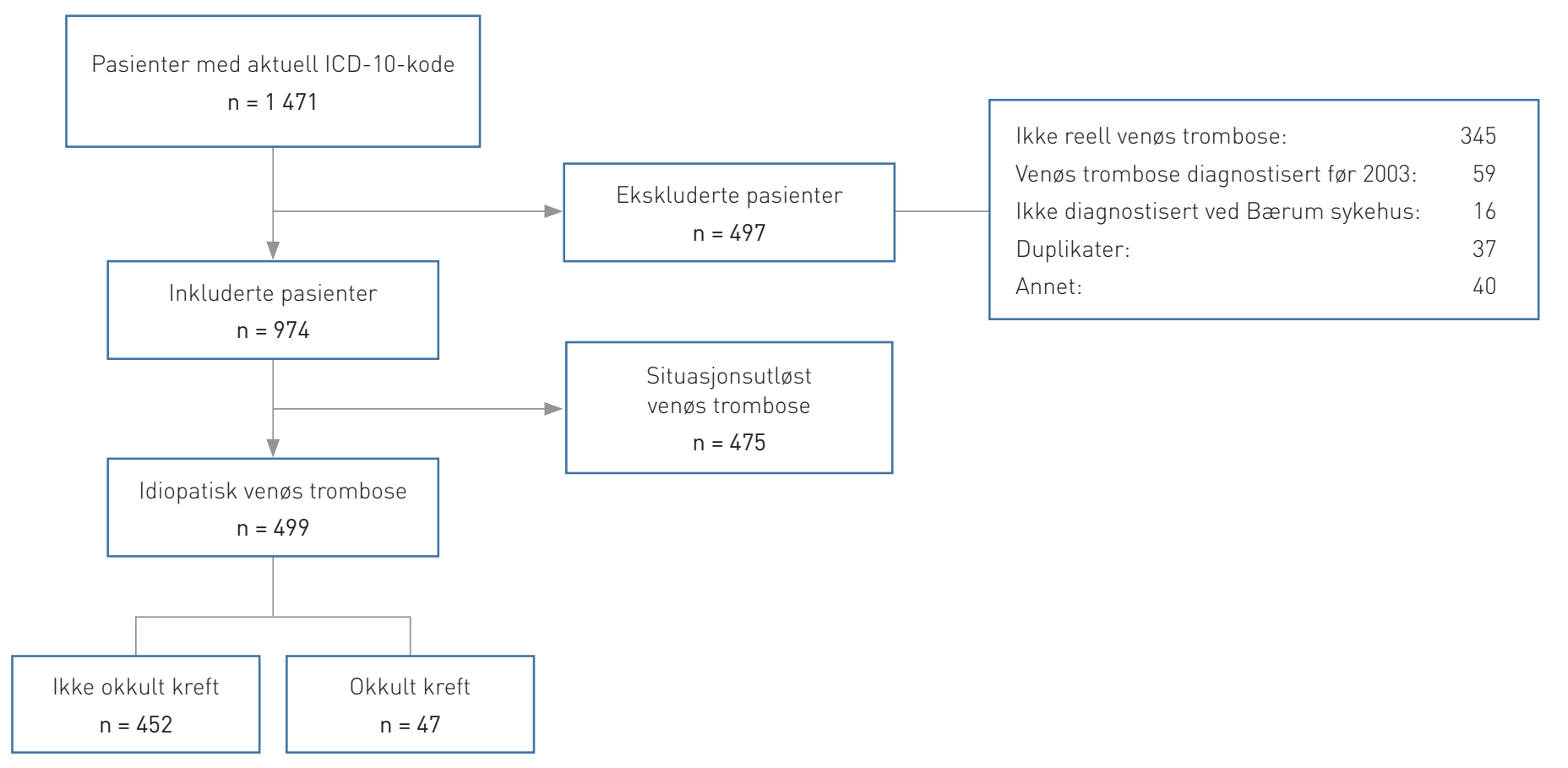

Figur 1 Flytskjema for studiepopulasjonen

skjønnsmessig vurdering, der vurderingen som de behandlende leger opprinnelig hadde gjort, ble tillagt betydelig vekt.

Pasienter ble ekskludert hvis den aktuelle venøse trombosen var assosiert med kjent kreftsykdom, operative inngrep eller skader siste tre måneder, immobilisering på grunn av sykdom, svangerskap/fødsel, østrogenbehandling, arvelig trombosedisposisjon (unntatt heterozygot faktor V Leiden-mutasjon), alvorlig infeksjon, alvorlig dehydrering, intravenøst stoffmisbruk eller sentralt venekateter.

Venøs trombose uten disse eksklusjonskriteriene ble definert som idiopatisk venøs trombose. Alle som hadde gjennomgått idiopatisk venøs trombose fikk forespørsel om å delta $i$ et oppfølgingsprosjekt der de ble bedt om å fylle ut et spørreskjema. Deltakerne ble blant annet spurt om de hadde hatt annen sykdom etter venetrombosen. For alle som besvarte undersøkelsen, ble det i tillegg gjort journalgjennomgang med tanke på kreftsykdom, og alle opplysninger om kreft ble verifisert i journal. Når det gjaldt dem som var døde eller ikke besvarte undersøkelsen, ble det gjort journalgjennomgang med tanke på kreftsykdom etter venøs trombose. I disse tilfellene er kreftdiagnosen basert på journalopplysninger alene.

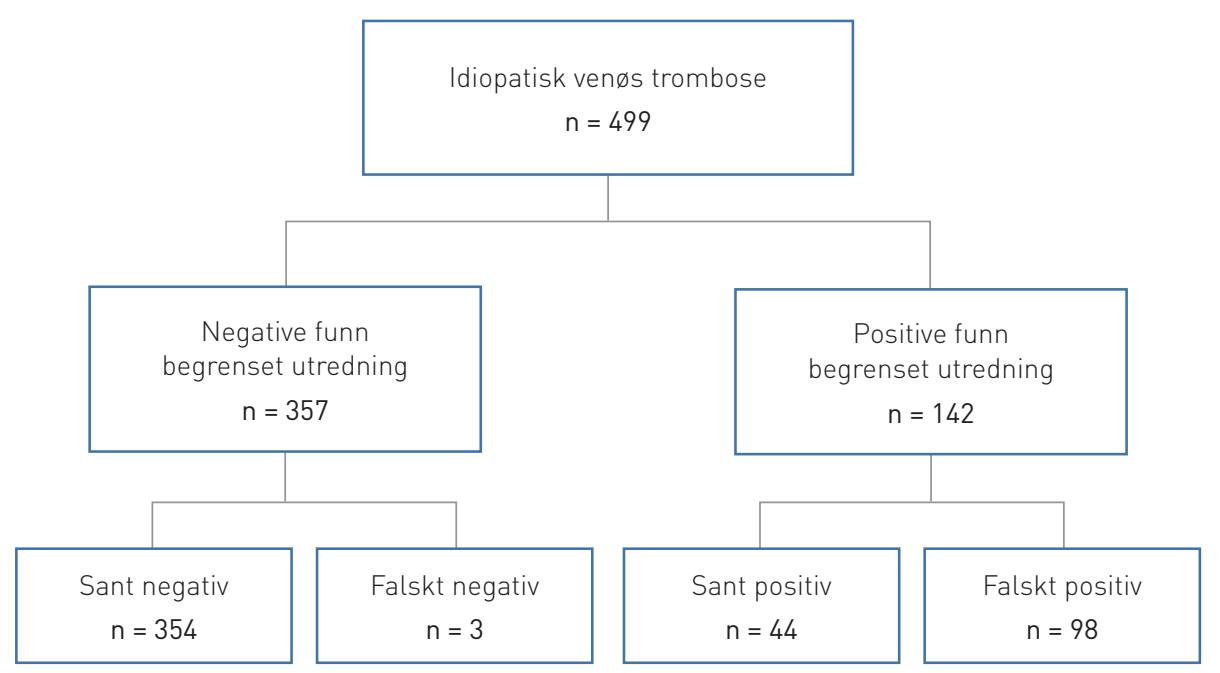

Figur 2 Utfall av begrenset utredning av pasienter med idiopatisk venøs trombose

«Okkult kreft» ble definert som kreftsykdom som ikke var kjent da det ble påvist venøs trombose, men som ble oppdaget $i$ løpet av de første 12 måneder etter diagnosetidspunktet.

Den begrensede utredningen ved Bærum sykehus innebærer anamnese med vekt på malignitetssuspekte symptomer, kroppsundersøkelse med lymfeknuteundersøkelse og rektal eksplorasjon, palpatorisk undersøkelse av testikler og prostata hos menn og palpatorisk brystundersøkelse hos kvinner. Det tas standard blodprøver, inkludert hematologiske prøver, lever- og nyrefunksjon, CRP og, hos menn, PSA-test. Urin og avføring undersøkes med tanke på forekomst av blod. I tillegg henvises kvinner til mammografi og gynekologisk undersøkelse hvis ikke dette er gjort de siste 12 måneder. Hvis CT thorax ikke er utført i forbindelse med diagnostikk av lungeembolisme, blir røntgen thorax tatt som del av malignitetsutredningen. Ytterligere undersøkelser gjøres kun hvis unormale funn ved den begrensede utredningen tilsier det. Hvilke undersøkelser som videre utføres, er avhengig av hvilke unormale funn som gjøres.

Dataene er beskrevet med frekvensfordeling for kategoriske variabler og med median (minimum/maksimum) for kontinuerlige variabler, da disse ikke var normalfordelt. Resultatet av undersøkelsene som gjøres ved begrenset malignitetsutredning ble angitt som positivt hvis det var angitt avvik fra det normale i journalen og som negativt hvis det ikke var notert unormale funn. 
Forekomst av nye krefttilfeller hos pasientene med idiopatisk venøs trombose første år etter trombosen ble sammenliknet med insidens av kreftsykdom i en alders- og kjønnsmatchet kontrollgruppe fra den generelle befolkningen i Asker og Bærum fra årene 2003-08 basert på tall innhentet fra Kreftregisteret spesifikt for dette prosjektet. Khikvadrattest ble brukt i denne sammenlikningen. Negativ prediktiv verdi ble brukt for å vurdere om man ved begrenset malignitetsutredning hos den aktuelle pasientgruppen vil være i stand til å utelukke okkult kreft.

Utgangspunktet for studien var Tromboseregisteret ved Bærum sykehus, som er samtykkebasert, godkjent av regional etisk komité og tilrådet utvidet av personvernombudet for forskning. Alle som blir behandlet for venøs trombose ved Tromboseklinikken, Bærum sykehus forespørres når de får diagnosen.

Hos dem som samtykker, registreres data om trombosen, behandling, utløsende faktorer og relaterte tilstander. Alle opplysninger om kreftsykdom senere er hentet inn retrospektivt, som beskrevet over, og innlemmet i Tromboseregisteret for dem som har samtykket til dette. Når det gjelder døde eller de som ikke hadde avgitt samtykke, ble det gjort journalgjennomgang som ledd i kvalitetssikring etter $\S 26$ i helsepersonelloven.

All behandling av personopplysninger er gjennomført som beskrevet i tilrådingen fra personvernombudet. Tilrådingen innebærer anonymisering der det ikke foreligger samtykke.

\section{Resultater}

I perioden 2003-08 ble 974 pasienter behandlet for venøs trombose ved Bærum sykehus. Av disse identifiserte vi 499 med idiopatisk venøs trombose (fig 1). Pasientkarakteristika og trombosens lokalisering er presentert i tabell 1. 129 var døde da denne undersøkelsen ble gjennomført. Av de 370 som fortsatt var i live, besvarte 295 (80\%) spørreskjemaet.

Av de 499 pasientene fikk 47 (9,4\%; $95 \%$ KI 7,1-12,3) kreft i løpet av de første 12 månedene etter påvisning av venøs trombose (fig 1). Dette er signifikant høyere enn årlig forekomst av kreft i den generelle befolkning i Asker og Bærum i samme tidsperiode $(1,9 \%$; $95 \% \mathrm{KI} 0,9-3,5 ; \mathrm{p}<0,001)$. Når det gjelder kreftsykdommens lokalisering, var de fleste organsystemer representert, med lunge $(n=10)$, prostata $(n=7)$, ukjent origo $(n=7)$, pancreas $(n=5)$, colon/ rectum $(n=3)$ og bryst $(n=3)$ som de vanligste.

Begrenset utredningsstrategi, med videre utredning kun hvis kliniske eller laboratoriemessige avvik tilsa det, ga negative funn $\mathrm{i}$ $72 \%$ av tilfellene (fig 2 ). Resten av pasientene fikk positive resultater $i$ en eller flere enkeltstående undersøkelser i utredningsstrategien.

Hos tre av dem som senere fikk påvist okkult kreft, var det ingen funn ved begrenset utredning, mens 98 pasienter med positive funn ved begrenset utredning ikke fikk påvist malign sykdom ved ytterligere utredning (fig 2). Den begrensede utredningsstrategien hadde en negativ prediktiv verdi på $99 \%$. Utredningsstrategien hadde en sensitivitet på $94 \%$ og en spesifisitet på $78 \%$. Det var ingen åpenbare forskjeller mellom gruppene som fikk eller ikke fikk påvist okkult kreft når det gjelder alder, kjønn eller trombosens lokalisering ( $\operatorname{tab} 2$ ).

\section{Diskusjon}

I denne retrospektive studien fikk $9,4 \%$ av pasientene med idiopatisk venøs trombose påvist kreftsykdom i løpet av det første året etter trombosen, mot $1,9 \%$ i den generelle befolkning når man tar hensyn til alder, kjønnsfordeling og geografiske forhold. Det var ingen forskjell i alder, kjønn eller trombosens lokalisering mellom dem som fikk påvist okkult kreft og dem som ikke fikk det. Den begrensede malignitetsutredningen etter påvist idiopatisk venøs trombose som anvendes ved Bærum sykehus hadde en høy negativ prediktiv verdi ( $99 \%$ ).

Forekomsten av okkult kreft hos pasienter med idiopatisk venøs trombose $\mathrm{i}$ vår studie er i samme størrelsesorden som det som er rapportert i internasjonal litteratur $(3,6-14$, $20)$. Så vidt vi kjenner til, er det ikke tidligere publisert tilsvarende undersøkelser fra Norge. Til forskjell fra det man har funnet $\mathrm{i}$
Tabell 1 Demografiske data for pasienter med idiopatisk venøs trombose diagnostisert ved Bærum sykehus i perioden 1.1. 200331.12. $2008(\mathrm{~N}=499)$. Antall (\%) dersom ikke annet er angitt. Noen pasienter har venøs trombose flere steder

\begin{tabular}{|c|c|c|}
\hline Demografiske variabler & \multicolumn{2}{|c|}{ Data } \\
\hline $\begin{array}{l}\text { Alder (år), median } \\
\text { (min-maks) }\end{array}$ & 75 & $(20-97)$ \\
\hline \multicolumn{3}{|l|}{ Kjønn } \\
\hline Kvinne & 233 & (47) \\
\hline Dyp venetrombose, bein & 244 & (49) \\
\hline Lår & 175 & (35) \\
\hline Legg & 69 & (14) \\
\hline Høyre & 110 & (45) \\
\hline Venstre & 135 & (55) \\
\hline Lungeembolisme & 274 & (55) \\
\hline Venøs trombose annet sted & 17 & $(3,4)$ \\
\hline
\end{tabular}

en del andre studier, fant vi ingen forskjell i aldersfordelingen mellom dem som utviklet kreft første året og dem som ikke gjorde det. Det taler for at man ikke kun bør gjøre malignitetsutredning i aldersgruppen over 60 år, slik enkelte andre har foreslått $(6,21$, 22). Da vi heller ikke fant noen forskjell mellom menn og kvinner, bør begge kjønn utredes i samme grad.

Ut fra tidligere studier er det antydet at

Tabell 2 Sammenlikning av pasienter med og uten okkult kreft etter diagnostisert idiopatisk venøs trombose ved Bærum sykehus i perioden 1.1. $2003-1.12 .2008$ ( $N=499$ ). Antall (\%) dersom annet ikke er angitt. Noen pasienter har venøs trombose flere steder

\begin{tabular}{|c|c|c|c|c|}
\hline \multirow[b]{2}{*}{ Alder (år), median (min-maks) } & \multicolumn{2}{|c|}{$\begin{array}{c}\text { Pasienter } \\
\text { med okkult kreft } \\
\text { ( } \mathrm{n}=47)\end{array}$} & \multicolumn{2}{|c|}{$\begin{array}{c}\text { Pasienter } \\
\text { uten okkult kreft } \\
\text { (n }=452)\end{array}$} \\
\hline & 75 & $(23-91)$ & 75 & $-97)$ \\
\hline \multicolumn{5}{|l|}{ Kjønn } \\
\hline Kvinne & 18 & (38) & 215 & (48) \\
\hline Mann & 29 & (62) & 237 & (52) \\
\hline Dyp venetrombose & 24 & (51) & 220 & (49) \\
\hline Lår & 17 & (36) & 158 & (35) \\
\hline Legg & 7 & $(15)$ & 62 & $(14)$ \\
\hline Høyre & 11 & (23) & 99 & (22) \\
\hline Venstre & 14 & (30) & 121 & (27) \\
\hline Lungeembolisme & 27 & (57) & 247 & (55) \\
\hline Venøs trombose annet sted & 3 & (6) & 14 & (3) \\
\hline
\end{tabular}


trombosens lokalisering har betydning for hvor sannsynlig det er at pasienten har en underliggende kreftsykdom $(22,23)$, og at visse krefttyper er mer assosiert med venøs trombose enn andre $(4,21,24)$. Vi fant ingen holdepunkter for dette $\mathrm{i}$ vårt materiale. Antall tilfeller av okkult kreft i vår studie er så begrenset at vi ikke kan belegge dette med stor statistisk tyngde, men siden krefttilfellene er så forskjellige, kan man ikke uten videre unnlate å lete i noen spesielle organer.

Utvidet utredningsstrategi innebærer oftest CT thorax og abdomen, i tillegg til endoskopi. Ultralydundersøkelse av abdomen, som ble mye brukt tidligere, har vist seg lite nyttig i malignitetsutredning (25). CT-undersøkelse av thorax og abdomen er sannsynligvis den mest nyttige radiologiske undersøkelsen. Strålebelastningen kan imidlertid være betydelig, og undersøkelsen er ressurskrevende både for helsevesenet og pasienten (25-27).

Grundige kostnad-nytte-analyser når det gjelder utvidet malignitetsutredning er kompliserte. Få studier, ei heller vår, er utført i denne hensikt, og det kan synes som om kostnadsestimatene varierer fra land til land $(25,28)$. Den største og seneste studien som omhandler temaet konkluderer med at økonomiske resultater vanskelig kan legges til grunn i en kostnad-nytte-analyse (29). Kostnadene er påvirket av mange falskt positive funn ved utvidet utredning som krevde ytterligere utredning.

Det fremkom falskt positive funn hos 98 av pasientene i vår studie. Den ekstrabelastningen dette innebærer bør stå sentralt i vurderingen av hvilken grad av utredning som skal velges (30).

Det er gode holdepunkter for at en omfattende malignitetsutredning ved idiopatisk venøs trombose vil avsløre flere krefttilfeller tidligere $(6,28)$. Ut fra aktuell litteratur er det imidlertid fortsatt uavklart om en slik utredning har et akseptabelt kostnad-nytte-forhold ut fra belastningen på hele pasientgruppen og på helsevesenet på den ene side og det antall pasienter som får bedret prognose og redusert mortalitet på den annen.

Det er reist tvil om påvisning av okkult kreft på et tidligere tidspunkt faktisk gir noen prognostisk gevinst, fordi kreftsykdommen i de fleste tilfeller allerede er kommet langt ved funn av idiopatisk venøs trombose $(9$, 31). I vår studie fikk tre pasienter påvist okkult kreft etter at begrenset utredning ikke hadde avdekket tegn til malign sykdom. Vi kan ikke utelukke at tidlig diagnose kunne hatt betydning for prognosen for noen av disse, hvilket kunne tale for å gjøre mer omfattende utredning hos alle. Det store antallet man måtte undersøke og strålebelastningen hele gruppen ville bli utsatt for, taler imidlertid imot omfattende utredning hos alle.

Den eneste randomiserte studien der man sammenliknet omfattende utredning med ingen utredning med tanke på okkult kreftsykdom, viste at man kunne oppdage okkult kreftsykdom på et tidligere tidspunkt, men den ga ikke noe klart svar på om det hadde betydning for prognosen (19). Studien reiste flere etiske problemstillinger knyttet til hvordan kontrollgruppen skulle håndteres når det gjaldt informasjon, og mange av pasientene i kontrollgruppen ble utredet mer enn de skulle fordi noen leger mente det var uetisk å la være. I tillegg ble studien avbrutt etter fem år med 201 inkluderte pasienter av i alt 1000 planlagte. Dette gjør at resultatene er vanskelige å tolke.

Den høye forekomsten av okkult kreftsykdom understreker viktigheten av å ha en god plan for malignitetsutredning. Dette er spesielt viktig $\mathrm{i}$ disse dager, når flere arbeidsoppgaver overføres fra spesialisthelsetjenesten til primærhelsetjenesten som følge av samhandlingsreformen og nye perorale antikoagulasjonsmidler tas i bruk (9). Begge disse forhold vil føre til økt poliklinisk behandling av pasienter med venøs trombose. Mange vil trolig bare ha ett enkelt poliklinisk besøk på sykehuset i akuttfasen før han/hun blir overført til primærhelsetjenesten for videre oppfølging. Oppgaver som malignitetsutredning vil derfor i stor grad måtte overtas av fastlegene.

Vår studie har begrensninger. Den er ikke gjennomført prospektivt med tanke på å avdekke okkult kreft. Undersøkelse av pasienter med idiopatisk venøs trombose har imidlertid vært detaljert beskrevet i prosedyrer, og journalføringen ved diagnosetidspunktet er systematisk gjennomført av en kompetent gruppe leger og sykepleiere ved Tromboseklinikken, Bærum sykehus.

Vi kan ikke utelukke at de som ikke har besvart spørreskjemaet om sin helsetilstand etter å ha hatt venøs trombose, har fått påvist kreft uten at vi har fått kjennskap til det. Men pasienter i Asker og Bærum har alle Bærum sykehus som sitt primærsykehus, slik at de fleste med kreftsykdom ville blitt henvist dit. Hvis det har vært flere krefttilfeller enn dem vi har registrert, betyr det at forekomsten av okkult kreft er enda høyere enn de $9,4 \%$ vi har funnet, og at man ved begrenset utredning kan ha oversett flere enn de tre tilfellene vi har registrert.

\section{Konklusjon}

Nær $10 \%$ av pasientene med idiopatisk venøs trombose hadde okkult kreftsykdom. Begrenset utredning med tanke på underliggende kreftsykdom avslørte de aller fleste av disse tilfellene og synes å være en hensiktsmessig strategi når det gjelder pasienter med idiopatisk venøs trombose. Hos omkring $20 \%$ var det avvik ved begrenset utredning uten at det ble påvist kreftsykdom.
Samhandlingsreformen og innføringen av nye behandlingsformer for venøs trombose vil medføre at hovedansvaret for oppfølgingen av disse pasientene vil bli overført til primærhelsetjenesten. Det er da spesielt viktig at man lager gode planer for hva som skal gjøres av malignitetsutredning. Vår studie tyder på at malignitetsutredning bør gjøres uavhengig av pasientens alder og kjønn og trombosens lokalisering.

\section{Vigdis Bache Semb (f. 1970)}

har mastergrad i helsefagvitenskap, er sykepleier ved Tromboseklinikken (Medisinsk poliklinikk) og forskningssykepleier

Forfatter har fylt ut ICMJE-skjemaet og oppgir ingen interessekonflikter.

\section{Arnljot Tveit (f. 1958)}

er spesialist $\mathrm{i}$ indremedisin, avdelingssjef og prosjektleder for flere kliniske og epidemiologiske forskningsprosjekter med vekt på hjerte- og karsykdom og trombose. Han har vært faglig ansvarlig for Tromboseklinikken ved Bærum sykehus i mange år.

Forfatter har fylt ut ICMJE-skjemaet og oppgir følgende interessekonflikter: Han er medlem av vitenskapelig rådgivningsgruppe for BristolMyers Squibb, Bayer, MSD og Sanofi-Aventis og har mottatt konsultasjonshonorar/foredragshonorar fra Bayer, Boehringer-Ingelheim, Sanofi-Aventis, Nycomed og Pfizer.

\section{Litteratur}

1. Semb VB. Idiopatisk venøs trombose og underliggende malign sykdom. I hvilken grad bør det søkes etter okkult kreft? Oslo: Universitetet i Oslo, 2012: 70

2. Trousseau A. Lecture XCV - Phlegmatia alba dolens. London: The new Sydham Society, 1872

3. Otten HM. Prins MH. Venous thromboembolism and occult malignancy. Thromb Res 2001: 102: V187-94

4. Sørensen HT, Mellemkjær L, Olsen JH et al. Prognosis of cancers associated with venous thromboembolism. N Engl J Med 2000; 343: 1846-50.

5. White RH. The epidemiology of venous thromboembolism. Circulation 2003; 107 (suppl 1): 4I-8.

6. Carrier M, Le Gal G, Wells PS et al. Systematic review: the Trousseau syndrome revisited: should we screen extensively for cancer in patients with venous thromboembolism? Ann Intern Med 2008; 149: 323-33

7. Monreal M, Lensing AW, Prins $\mathrm{MH}$ et al. Screening for occult cancer in patients with acute deep vein thrombosis or pulmonary embolism. J Thromb Haemost 2004; 2: 876-81

8. Jara-Palomares L, Rodríguez-Matute C, ElíasHernández T et al. Testing for occult cancer in patients with pulmonary embolism: results from a screening program and a two-year follow-up survey. Thromb Res 2010; 125: 29-33.

9. Van Doormaal FF, Terpstra W, Van Der Griend R et al. Is extensive screening for cancer in idiopathic venous thromboembolism warranted? J Thromb Haemost 2011; 9: 79-84. 
10. Enguídanos MJ, Todolí JA, Saro E et al. Usefulness of the tumor markers in the diagnosis of idiopathic deep venous thrombosis associated cancer. An Med Interna 2002; 19: 561-6.

11. Cailleux N, Marie I, Primard E et al. Thrombophlebitis and cancer: evaluation of the diagnostic value of abdominal ultrasonography in the acute phase of a deep venous thrombosis. Report of 148 consecutive examinations. J Mal Vasc 1997; 22: 322-5

12. Bastounis EA, Karayiannakis AJ, Makri GG et al. The incidence of occult cancer in patients with deep venous thrombosis: a prospective study. J Intern Med 1996; 239: 153-6.

13. Monreal M, Lafoz E, Casals A et al. Occult cancer in patients with deep venous thrombosis. A systematic approach. Cancer 1991; 67: 541-5.

14. Monreal M, Casals A, Boix J et al. Occult cancer in patients with acute pulmonary embolism. A prospective study. Chest 1993; 103: 816-9

15. Farge D, Debourdeau P, Beckers M et al. International clinical practice guidelines for the treatment and prophylaxis of venous thromboembolism in patients with cancer. J Thromb Haemost 2013; 11: $56-70$.

16. Torbicki A, Perrier A, Konstantinides S et al. Guidelines on the diagnosis and management of acute pulmonary embolism: the Task Force for the Diagnosis and Management of Acute Pulmonary Embolism of the European Society of Cardiology (ESC). Eur Heart J 2008: 29: 2276-315.

17. Chong LY, Fenu E, Stansby $G$ et al. Management of venous thromboembolic diseases and the role of thrombophilia testing: summary of NICE guidance. BMJ 2012; 344: e3979.

18. Rosovsky R, Lee AY. Evidence-Based Mini-Review: Should all patients with idiopathic venous thromboembolic events be screened extensively for occult malignancy? Am Soc Hematol Educ Program 2010; 2010: $150-2$.

19. Piccioli A, Lensing AW, Prins MH et al. Extensive screening for occult malignant disease in idiopathic venous thromboembolism: a prospective randomized clinical trial. J Thromb Haemost 2004; 2: $884-9$.

20. White $\mathrm{RH}, \mathrm{Chew} H \mathrm{H}$, Zhou H et al. Incidence of venous thromboembolism in the year before the diagnosis of cancer in 528,693 adults. Arch Intern Med 2005; 165: 1782-7.

21. White RH. Cancer begets venous thromboembolism, but is venous thromboembolism a risk factor for cancer? J Thromb Haemost 2009; 7: 543-5.

22. Trujillo-Santos J, Prandoni P, Rivron-Guillot K et al. Clinical outcome in patients with venous thromboembolism and hidden cancer: findings from the RIETE Registry. J Thromb Haemost 2008; 6: $251-5$

23. Tafur AJ, Kalsi H, Wysokinski WE et al. The association of active cancer with venous thromboembolism location: a population-based study. Mayo Clin Proc 2011; 86: 25-30.

24. Caine GJ, Stonelake PS, Lip GY et al. The hypercoagulable state of malignancy: pathogenesis and current debate. Neoplasia 2002; 4: 465-73.

25. Di Nisio M, Otten HM, Piccioli A et al. Decision analysis for cancer screening in idiopathic venous thromboembolism. J Thromb Haemost 2005; 3 : 2391-6.

26. Brenner DJ. Should we be concerned about the rapid increase in CT usage? Rev Environ Health 2010; 25: 63-8

27. Hurwitz LM, Reiman RE, Yoshizumi TT et al. Radiation dose from contemporary cardiothoracic multidetector CT protocols with an anthropomorphic female phantom: implications for cancer induc tion. Radiology 2007: 245: 742-50.

28. Piccioli A, Lensing AW. Prins $\mathrm{MH}$ et al. Extensive screening for occult malignant disease in idiopathic venous thromboembolism: a prospective randomized clinical trial. J Thromb Haemost 2004 2: $884-9$.

29. Kleinjan A, van Doormaal FF, Prins MH et al. Limitations of screening for occult cancer in patients with idiopathic venous thromboembolism. Neth J Med 2012; 70: 311-7.

30. Salz T, Richman AR, Brewer NT. Meta-analyses of the effect of false-positive mammograms on generic and specific psychosocial outcomes. Psychooncology 2010; 19: 1026-34.

31. Sørensen HT, Mellemkjær L, Steffensen HF et al. Incidens af cancer efter påvist primær dyb venetrombose eller lungeemboli. Läkartidningen 2000; 97: $1961-4$

Mottatt 7.3. 2013, første revisjon innsendt 4.7. 2013 godkjent 3.10. 2013. Redaktør: Trine B. Haugen. 